\title{
VARIATIONAL PRINCIPLES FOR SELF-ADJOINT OPERATOR FUNCTIONS ARISING FROM SECOND-ORDER SYSTEMS
}

\author{
Birgit JACOB, MATthias LANGER AND CARSTEN TRUnK
}

Abstract. Variational principles are proved for self-adjoint operator functions arising from variational evolution equations of the form

$$
\langle\ddot{z}(t), y\rangle+\mathfrak{d}[\dot{z}(t), y]+\mathfrak{a}_{0}[z(t), y]=0 .
$$

Here $\mathfrak{a}_{0}$ and $\mathfrak{d}$ are densely defined, symmetric and positive sesquilinear forms on a Hilbert space $H$. We associate with the variational evolution equation an equivalent Cauchy problem corresponding to a block operator matrix $\mathscr{A}$, the forms

$$
\mathfrak{t}(\lambda)[x, y]:=\lambda^{2}\langle x, y\rangle+\lambda \mathfrak{d}[x, y]+\mathfrak{a}_{0}[x, y],
$$

where $\lambda \in \mathbb{C}$ and $x, y$ are in the domain of the form $\mathfrak{a}_{0}$, and a corresponding operator family $T(\lambda)$. Using form methods we define a generalized Rayleigh functional and characterize the eigenvalues above the essential spectrum of $\mathscr{A}$ by a min-max and a max-min variational principle. The obtained results are illustrated with a damped beam equation.

Mathematics subject classification (2010): 47A56, 49R05, 47A10.

Keywords and phrases: Block operator matrices, variational principle, operator function, second-order equations, spectrum, essential spectrum, sectorial form.

\section{REFERENCES}

[1] T. YA. AzIzov And I. S. Iokhvidov, Linear Operators in Spaces with an Indefinite Metric, John Wiley \& Sons, 1989.

[2] H. T. BANKS AND K. ITO, A unified framework for approximation in inverse problems for distributed parameter systems, Control Theory and Adv. Tech. 4 (1988), 73-90.

[3] H. T. BANKS, K. ITO AND Y. WANG, Well posedness for damped second order systems with unbounded input operators, Differential Integral Equations 8 (1995), 587-606.

[4] P. BINDING, D. ESCHWÉ AND H. LANGER, Variational principles for real eigenvalues of self-adjoint operator pencils, Integral Equations Operator Theory 38 (2000), 190-206.

[5] J. BogNaR, Indefinite Inner Product Spaces, Springer, 1974.

[6] S. CHEN, K. LIU AND Z. LIU, Spectrum and stability for elastic systems with global or local KelvinVoigt damping, SIAM J. Appl. Math. 59 (1998), 651-668.

[7] R. J. Duffin, A minimax theory for overdamped networks, J. Rational Mech. Anal. 4 (1955), $221-$ 233.

[8] D. E. Edmunds And W. D. Evans, Spectral Theory and Differential Operators, Oxford University Press, 1987.

[9] D. ESCHWÉ AND M. LANGER, Variational principles for eigenvalues of self-adjoint operator functions, Integral Equations Operator Theory 49 (2004), 287-321.

[10] R. O. HRYNiv AND A. A. ShKalikov, Exponential stability of semigroups related to operator models in mechanics, Math. Notes 73 (2003), 657-664.

[11] B. JACOB, K. MorRis AND C. TRUnK, Minimum-phase infinite-dimensional second-order systems, IEEE Transactions on Automatic Control 52 (2007), 1654-1665.

[12] B. JACOB AND C. TRUNK, Location of the spectrum of operator matrices which are associated to second order equations, Oper. Matrices 1 (2007), 45-60. 
[13] B. JACOB AND C. TRUNK, Spectrum and analyticity of semigroups arising in elasticity theory and hydromechanics, Semigroup Forum 79 (2009), 79-100.

[14] B. JACOB, C. TRUNK AND M. WinkLMEIER, Analyticity and Riesz basis property of semigroups associated to damped vibrations, J. Evol. Equ. 8 (2008), 263-281.

[15] T. Kato, Perturbation Theory for Linear Operators, Second Edition, Springer, 1976.

[16] I. LASIECKA, Stabilization of wave and plate equations with nonlinear dissipation on the boundary, J. Differential Equations 79 (1989), 340-381.

[17] C. TRUnK, Spectral theory for operator matrices related to models in mechanics, Math. Notes $\mathbf{8 3}$ (2008), 843-850.

[18] M. TUCSNAK AND G. WeIss, How to get a conservative well-posed system out of thin air, Part II, SIAM J. Control Optim. 42 (2003), 907-935.

[19] H. Voss, Variational principles for eigenvalues of nonlinear eigenproblems, in: Numerical Mathematics and Advanced Applications - ENUMATH 2013, Lecture Notes in Computational Science and Engineering, vol. 103 (2015), 305-313.

[20] A. Weinstein And W. STEnger, Methods of Intermediate Problems for Eigenvalues, Academic Press, 1972.

[21] G. WeISS AND M. TUCSNAK, How to get a conservative well-posed system out of thin air, Part I, ESAIM Control Optim. Calc. Var. 9 (2003), 247-274. 